\title{
Managing COLlaboration WITHIN NETWORKS AND RELATIONSHIPS IN THE SERIOUS GAME OF AgRibusine SS MANAGEMENT USING SANDPILE MODEL
}

\author{
SaifulBukhori \\ Information System Department, Jember University, Indonesia
}

\begin{abstract}
This research develop the managing within network and relationship mechanism in agribusiness management through serious game. Agribusiness is represented as sand that work together in the market (sandpile) to maintain networks and relationships. This research apply agent base model for predicting activity network based on the parameters that exist in the collaboration. The result indicate that average selling, average buying and market price $(C K=4)$ are not approach the value of the open market but precisely coincide with eachother. Total bought and total sold are tend to be high value. This condition suggests a very tight competition. The average selling, average buying and market price $(C K=0.01)$ are approach the value of the open market. Total bought and total sold are not as high as total bought and total sold, by using $C K=4$, this condition shows the competition is not too tight.
\end{abstract}

\section{KEYWORDS}

Sandpile model, Serious game, Agribusiness management, Managing collaboration.

\section{INTRODUCTION}

The word of collaboration literally means working together [1]. This word is often used when individuals or organizations work together towards a common aim. The other words that are used to explain this situation are relationships, partnerships or alliances.

Benefits and motives related with inter-company collaboration were identified as follows: (a) to increase their market share [2], (b) to increase asset utilization [2], (c) to enhance customer service-reduction in lead times, customer complaints, etc [2], (d) to share and reduce the cost of product development [3], (e) to reduce time in product development [4], and (f) to decrease risk of failure of product development [5].

Networks and relationships in the collaborative enterprise can form a new and unique value by complementing, integrating and leveraging each other's capabilities and competencies [6]. Agribusiness requires a collaborative enterprise network, due to the complexity and number of interconnected firms.

Investment in the agribusiness companies is very expensive, high risk and uncertainty. The uncertainty caused by the project implementation delay and growth opportunities are very influential on the value of a project. Value of the project not only depends on cash flow and financial but also the uncertainty [7]. Therefore, it is necessary to analyse the value chains of agribusiness management before making a decision relating to investments. This research 
International Journal of Computer Science \& Information Technology (IJCSIT) Vol 6, No 5, October 2014

develops the managing collaboration within networks and relationships agribusiness management through serious game.

The value chain analysis is influenced by three elements: network structure, value added and governance. The network structure is a horizontal and vertical market relationship. Value added is a competitive aim of any business chain. Governance is an organizational arrangement between value chain peoples [8]. These elements should always be studied as a whole of the value chain's business environment.

The partnerships require careful consideration, experience and knowledge, the ability to estimate the costs as well as benefits and investments. Accordingly, each relationship should be considered from the perspective of buyer and perspective of supplier. These perspectives used to understand and assess the desired value outcomes of their relationship.

The decisions strategic are related to the management of collaboration (location and number of suppliers, the facility of production, distribution centres, warehouse and customers). Management of material, management of inventory, planning, forecasting, etc affect to decisions. Therefore, to measure the performance of the collaboration, it is necessary to study the network and relationship between the agribusiness enterprise collaboration. This relation can be described by using dynamic system.

The dynamics systems problem can be solved by using a cellular automata model. One of the cellular automata model is "running sandpile" dynamics. This model describe the stability problem and the scale problem of the difficulties standing in the way of understanding anomalous transport in magnetically confined plasmas; [9].

This research develops a managing collaboration within networks and relationships in agribusiness management using sandpile models through serious game. This model simulates collaborative networks and relationships that is expected to be used for a relationship management strategy.

The rest of this paper is organized as follows. The proposed sandpile model is described in section 2. Section 3 gives the investment analysis. Finally conclusions are given in section 4

\section{The Proposed SANDPiLe Model}

\subsection{Agribusiness Management Modelling}

This research uses the dynamic system model. One advantage of using dynamic system model over more traditional models is the inclusion of feedback effects. The feedback effects make the output of the model more realistic and expose the complexity deeper than other modelling techniques. Thus, interrelationships in the models can more easily identified by decision makers. Feedback effects occur in almost all levels. By learning a model of feedback, it can make the decision to change the real world, receive information about changes in the real world and use this new information. This perspective revises the understanding of the world and decision to bring the system closer to the goals we want to achieve [10].

Homer (1987) utilizes feedback in a dynamic system model to explain the emergence of medical technology by modelling how the adoption process motivates the diffusion of new technology [11]. He examines that adoption process is influenced by exogenous and endogenous factors. Exogenous factors such as the attributes of the technology, intervention of government, the initial perception, decision of new purchasing, and standards of performance. Whereas endogenous 
factors such as evaluation and support [12] as shown in Figure 1. In this research, Utilizes feedback in a dynamic system model to study the relationship management in order to enhance agribusiness investment.

The strategy, structure and decision rule in this research adopt the network model on company, suppliers and buyers as shown in Figure 2.

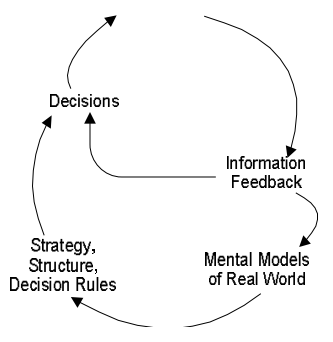

Figure 1. Double-loop learning [12]

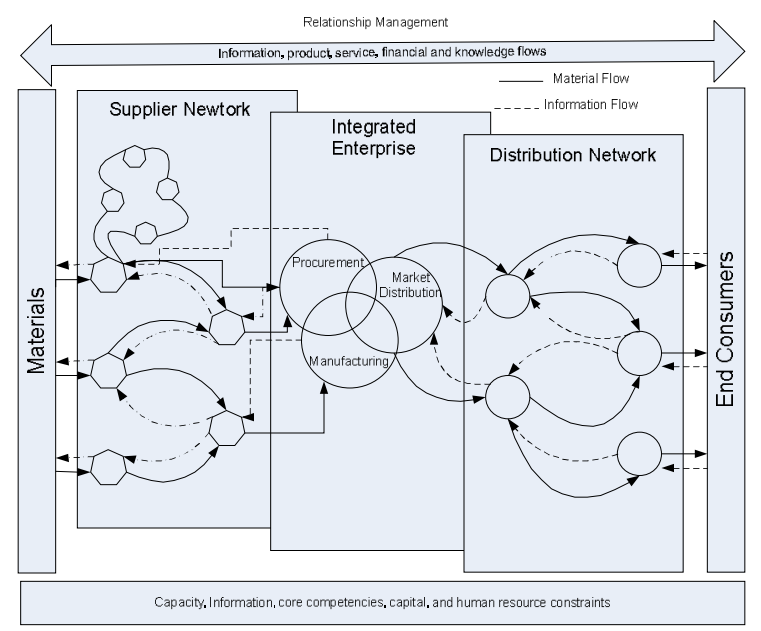

Figure 2. Network model on company, suppliers and buyers [13]

In a relationship, value is viewed as a process, dynamic, on both parties, and good value created by both parties [14].

The description of the nature of relationships in agribusiness enterprises above highlighted the traditional concept of firms. Traditionally firms were viewed as a discrete and independent entity. In determining the strategy that chosen, firms sought to reinforce independence [15]. This concept has been changed to be network based strategies. The contemporary concept is that firms are embedded in network or web of interdependent relationships and as such firms need a strategic approach to the management of such relationships. The following diagram (Figure 3.) illustrates the nature of relationships that modern day firms engage into in their day to day competitive environment [15].

The strategy of relationship management aims to increase the investment. Investment (I) depends on income at the time when the investment decisions are taken and on capital stock at the time when investment will be finished. The latter is a consequence of the fact that in time $t-T$ there are some investments, which will be finished between $\mathrm{t}-\mathrm{T}$ and $\mathrm{T}$. The assumption on this resaearch is the resulting capital in this period is considered when new investments are planned. 


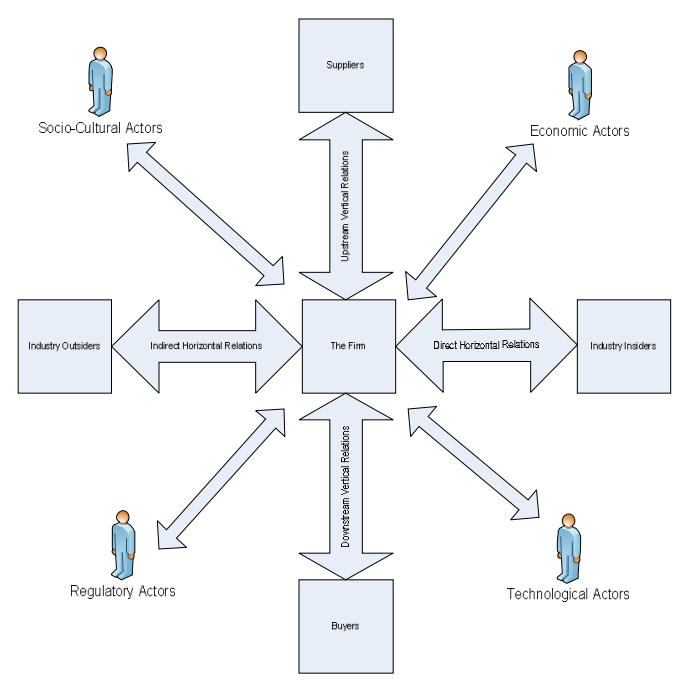

Figure 3. Relationship management strategies

The saving function (S) depends only on $\mathrm{Y}$ (gross product) and is linear such that $\mathrm{S}_{\mathrm{Y}}=\gamma \in$ $(0,1)$. Additionally. this research assume that the investment function $\mathrm{I}(\mathrm{Y}, \mathrm{K})$ separates in respect to its two arguments ( $\mathrm{Y}$ is gross product and $\mathrm{K}$ is capital stock) and $\mathrm{I}_{\mathrm{y}}>0, \mathrm{I}(\mathrm{K})$ is linear such that $\mathrm{I}_{\mathrm{K}}=\beta<0$ then

$$
\mathrm{I}(\mathrm{Y}, \mathrm{K})=\mathrm{I}(\mathrm{Y})+\beta \mathrm{K}
$$

After substituting the above assumption into the Kaldor-Kalecki dynamic system, we have

$$
\begin{aligned}
& \frac{\mathrm{dY}}{\mathrm{dt}}=\alpha \mathrm{I}(\mathrm{Y}(\mathrm{t}))+\alpha \beta \mathrm{K}(\mathrm{t})-\alpha \gamma \mathrm{Y}(\mathrm{t}) \\
& \frac{\mathrm{dK}}{\mathrm{dt}}=\mathrm{I}(\mathrm{Y}(\mathrm{t}-\mathrm{T}))+(\beta-\delta) \mathrm{K}(\mathrm{t})
\end{aligned}
$$

The critical points of delay system coincide with the corresponding points for finishing delay because stationary states do not depend on translation of time. The critical points of $\mathrm{K}(\mathrm{CK})$ is shown in Eq.4.

$$
\mathrm{CK}=\frac{\mathrm{I}(\mathrm{CY})}{\delta-\beta}
$$

and the critical points of $\mathrm{Y}(\mathrm{CY})$ is shown in Eq.5.

$$
\mathrm{CY} \rightarrow \mathrm{I}(\mathrm{CY}) \frac{\delta}{\beta-\delta}+\gamma \mathrm{CY}=0
$$

\subsection{Agribusiness Management Modeling Using Sandpile Model}

Independence of price changes is consistent with theoretical arguments in the stock market [16]. Based on data analysis shows that the price changes in the stock market may not be independent. While independent variables are always uncorrelated, it is not true that uncorrelated variables are always independent. As an example that direction is uncorrelated with the past: The facts prove that the price drop yesterday does not necessarily make them more falls today. Large price alteration tend to be followed by an alteration greater, change can be lead to positive or negative. 
Small alteration tends to be followed by an alteration smaller. The behaviour of price changes in the stock market can be analogous to the addition of sand in the sandpile.

In the research of the non-equilibrium critical area, cellular automata (CA) that are applied for self-organized criticality (SOC) have been widely used. In contrast to the usual continuous phase transitions, they are rapidly evolving towards critical without tuning control parameters. Sandpile Automata is the prototypical model for SOC that developed by Bak, Tang, and Wiesenfeld (BTW), Sandpile Automata is modelled with dynamic sand particles which leads to the stationary state and distributed on all length scales [17] This model identifying the sand grain as energy, stress, or pressure.

Agribusiness management modelling using sandpile model in this research is based on agribusiness market behaviour. The agribusiness market behaviors are: (a) A large number of independent agents participate in a market, (b) Each agent has some alternatives in making his decision, (c) The aggregate activity results in a market price, which is known to all, (d) Agents use the public price history to make their decisions.

This research adds two rules: trading activity only on their own trading activity and agents only consider its own experience. This research want to study the inherent dynamics of the market, in the absence of external Influences through a serious game. The real economy has both internal and external contributes. Serious game agribusiness management using sandpile model in this research illustrate the trading model applied to artificial market. The model of investment distribution using sandpile model as shown in Figure 4

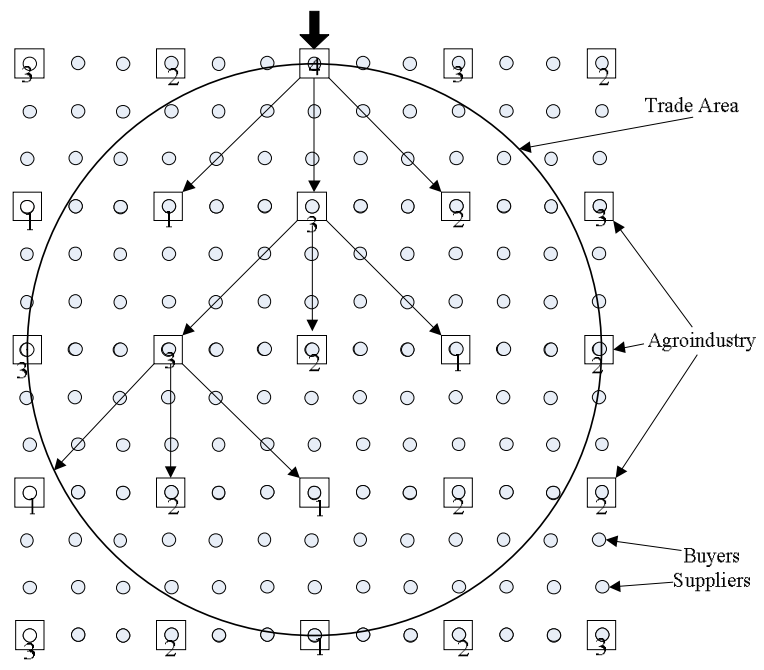

Figure 4. Investment distribution using sandpile model

Add a grain of sand or investment is shown in Eq.6.

$$
\mathrm{z}(\mathrm{x}, \mathrm{y}) \rightarrow \mathrm{z}(\mathrm{x}, \mathrm{y})+1
$$

The condition of the investment if $\mathrm{z}(\mathrm{x}, \mathrm{y}) \geq \mathrm{CK}$, in this simulation $\mathrm{CK}=4$, is shown in Eq.7.

$$
\mathrm{z}(\mathrm{x}, \mathrm{y}) \rightarrow \mathrm{z}(\mathrm{x}, \mathrm{y})-4
$$

The condition of the neighbourur agribusiness are shown in Eq.8 and Eq. 9.

$$
\begin{aligned}
& \mathrm{z}(\mathrm{x} \pm 1, \mathrm{y}) \rightarrow \mathrm{z}(\mathrm{x} \pm 1, \mathrm{y})+1 \\
& \mathrm{z}(\mathrm{x}, \mathrm{y} \pm 1) \rightarrow \mathrm{z}(\mathrm{x}, \mathrm{y} \pm 1)+1
\end{aligned}
$$


This research adopts the decentralization paradigm for modelling activity network system. The principal component of this system are adaptive agents consisting of four agents that are buyers agent, sellers agent, support agent, and competitors agent as shown in Figure 5.

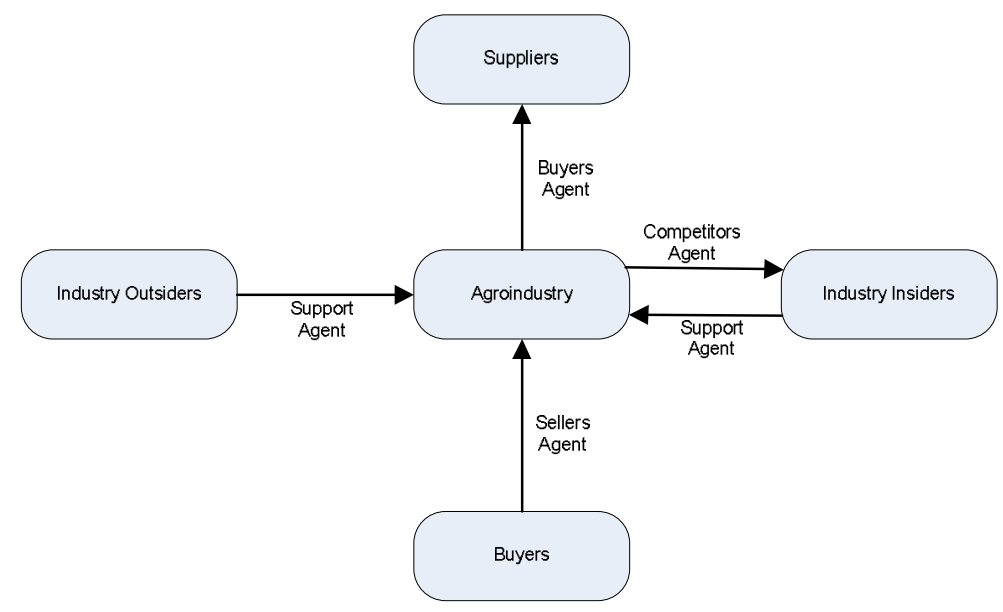

Figure 5. Decision of agribusiness based on information of 4 agents

Sellers agent give information concerning advantage that take income from buyers based on investment conditions. Buyers agent give information of advantage that take capital stock from supplier based on investment conditions. Support agent gives information concerning advantage that increased investment. Competitors agent gives information concerning advantage that decreased investment.

\section{INVESTMENT ANALYSIS}

Based on agribusiness management modeling and data modeling, there are inter-corporate network conditions possible forms: (1) mutual independence, (2)unbalanced independence, (3) mutual dependence, and (4) unbalanced dependence. These relational influenced by environmental capacity in this case is the analysis of relational conditions vertically, horizontally and other relationships as shown in Figure 6.

The scope of agribusiness consists of several sectors, among others: input, production, processing manufacturing and marketing. These sectors are directly related to the industry and trade. Industry related to the products and raw materials while trade associated with the distribution. Due to formation of the distribution network stock price tends to decline as shown in Figure 7. 
International Journal of Computer Science \& Information Technology (IJCSIT) Vol 6, No 5, October 2014
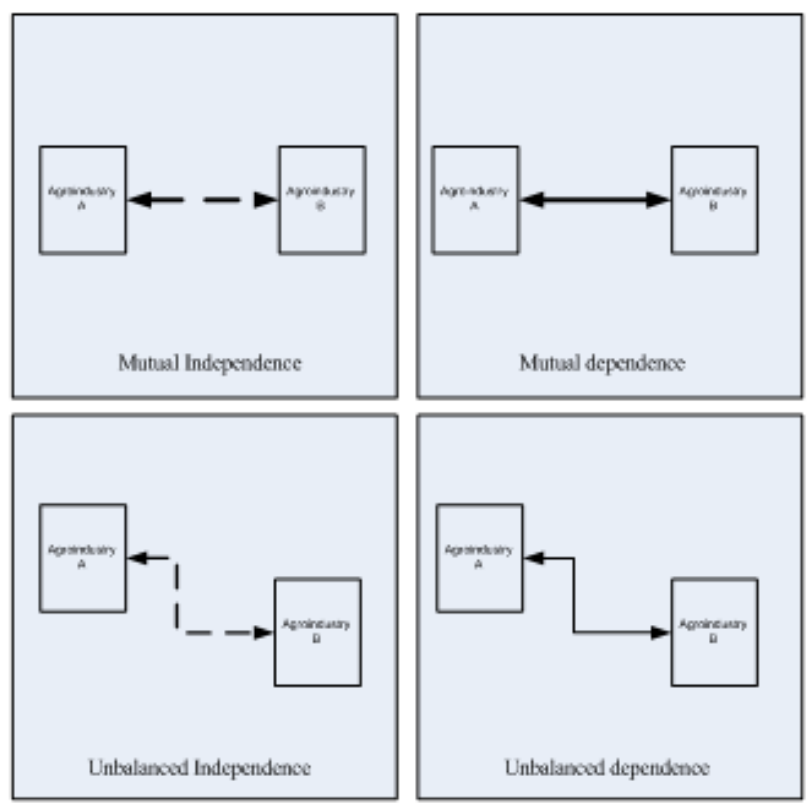

Figure 6. Inter-corporate network conditions

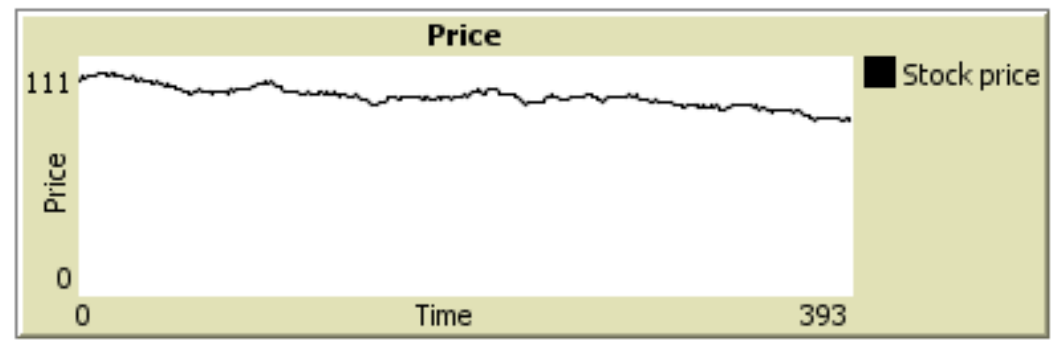

Figure 7. The graphs of stock price as functions of time

The condition of average selling, average buying, the market price and the open market in the serious game agribusiness management using sandpile model with parameter $\mathrm{CK}=4$ as shown in Figure 8 .

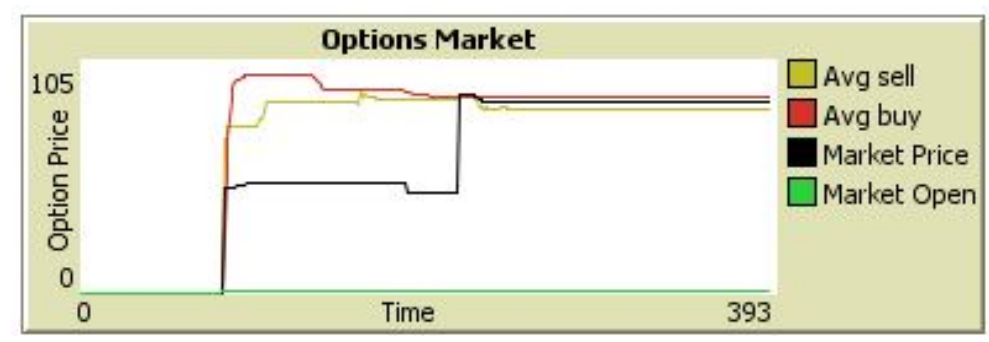

Figure 8. Option market using $\mathrm{CK}=4$

The average selling, average buying and market price, by using $\mathrm{CK}=4$, are not approach the value of the open market, but precisely the average value of selling, buying and average market price coincides with each other. 
International Journal of Computer Science \& Information Technology (IJCSIT) Vol 6, No 5, October 2014

The condition of total bought and total sold in the serious game agribusiness management using sandpile model with parameter CK $=4$ as shown in Figure 9.

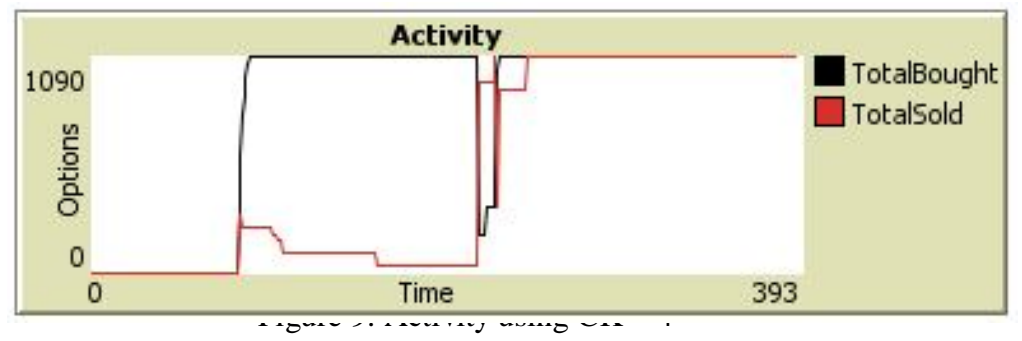

Total bought and total sold, by using $\mathrm{CK}=4$, are tend to be high value, this condition suggests a very tight competition.

The condition of average selling, average buying, the market price and the open market in the serious game agribusiness management using sandpile model with parameter $\mathrm{CK}=0.01$ as shown in Figure 10.

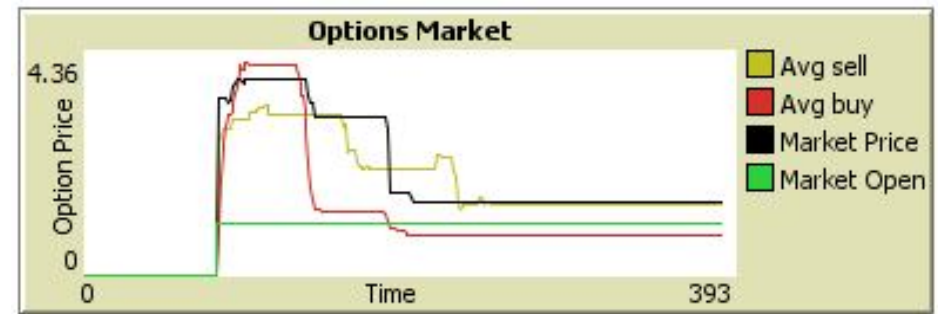

Figure 10 Option market using $\mathrm{CK}=0.01$

The average selling, average buying and market price, by using $\mathrm{CK}=0.01$, are approach the value of the open market.

The condition of total bought and total sold in the serious game agribusiness management using sandpile model with parameter $\mathrm{CK}=0.01$ as shown in Figure 11 .

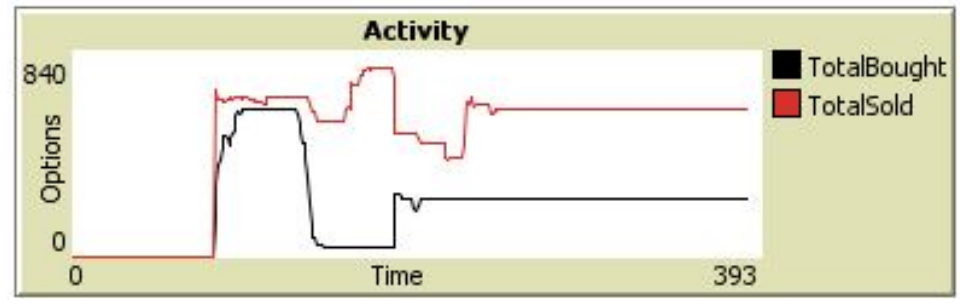

Figure 11. Activity using $\mathrm{CK}=0.01$

Total bought and total sold, by using CK $=0.01$ is not as high as total bought and total sold by using $\mathrm{CK}=4$, this condition shows the competition is not too tight.

Inventory of agroindustry-1 (AI-1), agroindustry-2 (AI-2) and supplier (S) by using CK= 0,01 as shown in Figure 12. 
International Journal of Computer Science \& Information Technology (IJCSIT) Vol 6, No 5, October 2014

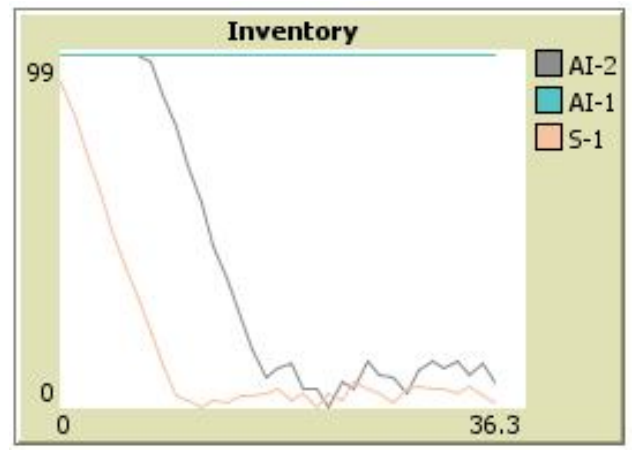

Figure 12. Inventory of A-1, A-2 and S-1 using CK =0,01

Inventory in the AI-1 (agro-industry is managed) tend to be fixed and not change due to the effect of the AI-2 and S. This indicates that the AI-1 does not play a role in market.

Total profit of Agroindustry-1 (AI-1), agroindustry-2 (AI-2) and supplier (S) by using CK= 0,01 as shown in Figure 13.

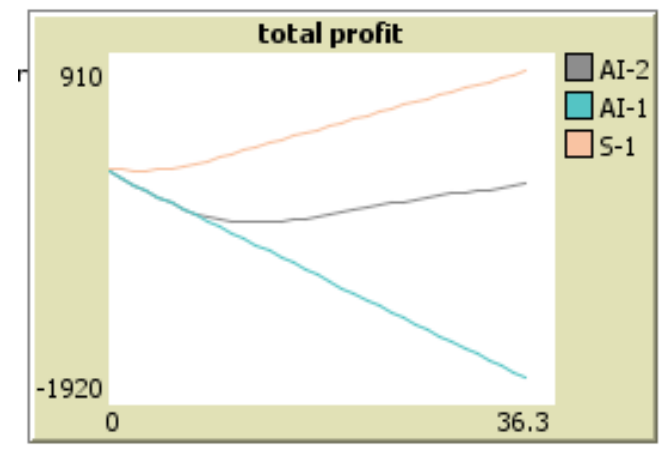

Figure 13. Total Profit Inventory of A-1, A-2 and S-1 using CK =0,01

Total profit in the AI-1 (agro-industry is managed) tends to go down and not affected by the AI-2 and $\mathrm{S}$. This indicates that the AI-1 was not too involved in the market.

Inventory of agroindustry-1 (AI-1), agroindustry-2 (AI-2) and supplier (S) by using CK= 4 as shown in Figure 14.

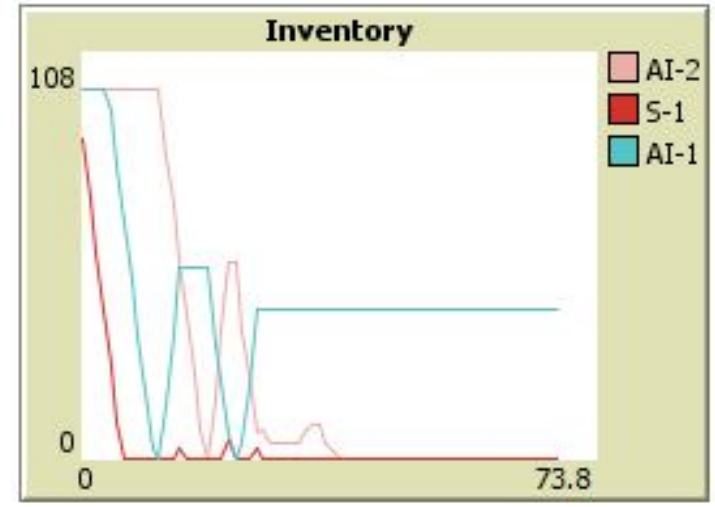

Figure 14. Inventory of A-1, A-2 and S-1 using CK = 4 
Inventory in the AI-1 (agro-industry is managed) tends to oscillate and is influenced by the $\mathrm{AI}-2$ and $\mathrm{S}$ follow market developments.

Total profit of Agroindustry-1 (AI-1), agroindustry-2 (AI-2) and supplier (S) by using $\mathrm{CK}=4$ as shown in Figure 15.

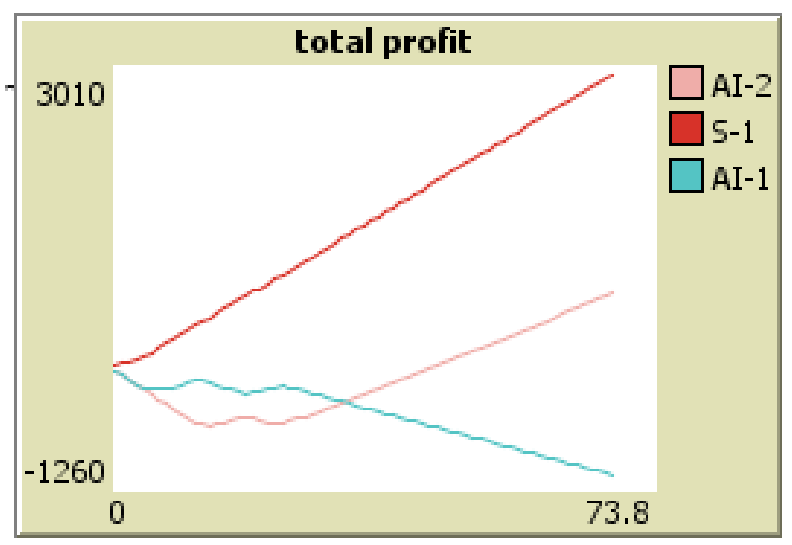

Figure 15. Total Profit Inventory of A-1, A-2 and S-1 using CK=4

Total profit in the AI-1 (agro-industry is managed) follow market developments.

\section{Conclusions}

The result of this research indicate that managing collaboration within networks and relationships in the serious game agribusiness management using sandpile model can detect average selling, average buying, market price, total bought, total sold, Inventory and total profit on the condition of the market by value of certain critical network between agroindustries.

The experimental results indicate that average selling, average buying and market price, by using $\mathrm{CK}=4$, are not approach the value of the open market but precisely coincide with each other. Total bought and total sold, by using $\mathrm{CK}=4$, are tend to be high value, this condition suggests a very tight competition. Inventory in the AI-1 (agro-industry is managed), by using $\mathrm{CK}=4$, tends to oscillate and is influenced by the AI-2 and S follow market developments. Total profit in the $\mathrm{AI}-1$, by using $\mathrm{CK}=4$, follow market developments.

The average selling, average buying and market price, by using $\mathrm{CK}=0.01$, are approach the value of the open market. Total bought and total sold, by using $\mathrm{CK}=0.01$ is not as high as total bought and total sold by using $\mathrm{CK}=4$, this condition shows the competition is not too tight. Inventory in the AI-1 (agro-industry is managed) tend to be fixed and not affected by the AI-2 and S. This indicates that the AI-1 does not play a role in market. Total profit in the AI-1 (agroindustry is managed) tends to go down and not affected by the AI-2 and S. This indicates that the AI-1 was not too involved in the market.

\section{REFERENCES}

[1] Jordan Jr. J.A. and Michel F.J., 2000, "Next Generation Manufacturing: Methods and Techniques",John Wiley \&Sons,Inc.

[2] Lewis, D.J, 1990, "Partnership for Profit: Structuring and Managing Strategic Alliances", The Free Press. 
International Journal of Computer Science \& Information Technology (IJCSIT) Vol 6, No 5, October 2014

[3] McLaren T, Head M.,Yuan Y., 2000, ”Supply Chain Collaboration Alternatives: Understanding the Expected Cost and Benefits", Internet Research: ElectronicNetworking Applications and Policy, Vol.12, No.4, pp.348-364

[4] McCarthy T.M., Golicic S.L., 2002, "Implementing Collaborative Forecasting to Improve Supply Chain Performance", International Journal of Physical Distribution \& Logistic Management, Vol.32, No. 6, pp.431-454, MCB University Press.

[5] Parker, Hamieda (2000),"Inter-firm Collaboration and the New Product Development Process", Industrial Management \& Data Systems, Vol.100, No 6, MCB University Press.

[6] Umit S Bititci, Veronica Martinez, PavelAlbores and JoniartoParung, 2004, " Creating and Managing Value in Collaborative Networks, International Journal of Physical Distribution and Logistics Management. Vol.34, p.251-268.

[7] SamehHachicha, Leila Kaaniche, FathiAbid, 2011, "Sequential investment and delay: an agribusiness firm case study", Agricultural Finance Review, Vol. 71 Iss: 2, pp.240 - 258

[8] Jacques H. Trienekens, 2011, Agricultural Value Chains in Developing Countries A Framework for Analysis, International Food and Agribusiness Management Review, Vol. 14, Issue 2, pp.51 - 82

[9] Newman, D. E., Carreras, B. A., and Diamond, P. H., 1996, The dynamics of sandpiles with a sheared flow, Physics Letters A, 218(1-2):58-63.

[10] Sterman, J. D., 1994, Learning in and about complex systems, System Dynamics Review, 10, 291 330

[11] Homer, J. B., 1987, A diffusion model with application to evolving medical technologies. Technological Forecasting and Social Change, 31, $197-218$

[12] Donna K. Fisher, Jonathan Norvell, Steven Sonka and Mark J. Nelson, 2001, Understanding technology adoption through system dynamics modeling: implications for agribusiness management, International Food and Agribusiness Management Review 3, 281-296

[13] Georgevitch, S. 2007. 787 Dreamliner: Business model \& supply chain overview. Presentation on March 15, 2007 at the Air Force Logistics Transformation Forum.

[14] Mandják, T. and Durrieu, F. 2000. "Understanding the non-economic value of business relationships", In 16th IMP Conference, eds. Ford, D, Bath, 1-17

[15] De Wit, B. \& Meyer, R. 2004. Strategy: Process, Content, Context. Third Edition. Thomson.

[16] Fama, Eugene.1970."Efcient Capital Markets: A Review of Theory and Empirical Work."Journal of Finance, pp. 383-417.

[17] P. Bak, C. Tang and K. Wiesenfeld, Phys. Rev. Lett. 59 , 381 (1987); Phys. Rev. A 38, 364 (1988)

\section{Authors}

SaifulBukhori received the bachelor degree in Electrical Engineering from Brawijaya University, Malang, Indonesia in 1993. He received both Magister Computer and Doctoral degrees in SepuluhNopember Institute of Technology (ITS), Surabaya, Indonesia, in 2003 and 2011, Currently, he is the staff of Information System Department in Jember University. His current interest's research areas are Informatics, Artificial Intelligence and Game Technology.

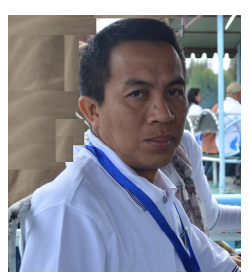

